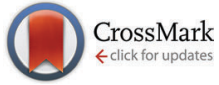

Cite this: New J. Chem., 2014, 38,6073

Received (in Victoria, Australia) 18th July 2014

Accepted 18th September 2014

DOI: 10.1039/c4nj01201a

www.rsc.org/njc

\title{
Bis(piperidinedithiocarbamato)pyridinecadmium(॥) as a single-source precursor for the synthesis of CdS nanoparticles and aerosol-assisted chemical vapour deposition (AACVD) of CdS thin films $\dagger$
}

\author{
Sixberth Mlowe, ${ }^{\mathrm{ab}}$ David J. Lewis, ${ }^{\mathrm{b}}$ M. Azad Malik, ${ }^{\mathrm{b}}$ James Raftery, $^{\mathrm{b}}$ Egid B. Mubofu, ${ }^{\mathrm{c}}$ \\ Paul O'Brien ${ }^{\mathrm{b}}$ and Neerish Revaprasadu*a
}

\begin{abstract}
The synthesis and single-crystal X-ray structure of bis(piperidinedithiocarbamato)pyridinecadmium(॥), $\left[\mathrm{Cd}\left(\mathrm{S}_{2} \mathrm{C}\left(\mathrm{NC}_{5} \mathrm{H}_{10}\right)\right)_{2}\left(\mathrm{NC}_{5} \mathrm{H}_{5}\right)\right]$ are reported and its use as a precursor for the synthesis of hexagonal CdS nanoparticles and CdS thin films is presented. Thermogravimetric analysis (TGA) of this complex showed clean decomposition in two steps to give CdS. Thermolysis of the complex in hexadecylamine at different temperatures in the range $190-270{ }^{\circ} \mathrm{C}$ gave CdS nanostructures including nanorods and oval shaped particles. The band gap of the as-synthesized CdS nanoparticles varied as the temperature was increased. CdS thin films with optical direct band gaps of ca. $2.4 \mathrm{eV}$ were deposited by aerosol-assisted chemical vapour deposition (AACVD) in the temperature range 350 to $450{ }^{\circ} \mathrm{C}$ using the same precursor. Powder X-ray diffraction (p-XRD) patterns of $\mathrm{CdS}$ nanoparticles and thin films confirmed the hexagonal phase of CdS.
\end{abstract}

\section{Introduction}

Dithiocarbamates are chelating ligands which form stable complexes with all the transition elements and also the majority of main group, lanthanide and actinide elements. ${ }^{1}$ Cadmium complexes of dithiocarbamates with alkyl groups of varying lengths have been extensively reported. ${ }^{2-8}$ These complexes have been used as precursors for the deposition of high quality cadmium sulfide thin films and nanoparticles. Recently our group has reported the use of heterocyclic dithiocarbamate complexes of cadmium for shape controlled CdS nanostructures. ${ }^{9-11}$ Four-coordinate complexes of cadmium are known to expand their coordination number by adding neutral nitrogen-containing ligands such as pyridine, bipyridine and 1,10-phenanthroline. ${ }^{12,13}$

Indeed, the physical properties and single crystal X-ray structural studies on numerous cadmium and zinc complexes comprising dithiocarbamate and aromatic nitrogen-containing chelating ligands such as pyridine, 2,2'-bipyridine and 1,10-phenanthroline have been

\footnotetext{
${ }^{a}$ Department of Chemistry, University of Zululand, Private Bag X1001, Kwa-Dlangezwa, 3886, South Africa. E-mail: RevaprasaduN@unizulu.ac.za; Fax: +27 35902 6568; Tel: +27359026152

${ }^{b}$ Schools of Chemistry and Materials Science, The University of Manchester, Oxford Road, Manchester, M13 9PL, UK

${ }^{c}$ Department of Chemistry, University of Dar es Salaam, P.O. Box 35061,

Dar es Salaam, Tanzania

$\dagger$ Electronic supplementary information (ESI) available. CCDC 984434. For ESI and crystallographic data in CIF or other electronic format see DOI: 10.1039/ c4nj01201a
}

reported. ${ }^{14-17}$ These five and six coordinate complexes showed increased electron density at the metal centre. Thermal properties of these adducts include increased volatility upon introduction of the Lewis base ligands containing nitrogen. ${ }^{18}$ Studies on the effect of pyridine and other nitrogen donor ligands in heterocyclic cadmium dithiocarbamate complexes on properties of CdS nanoparticles have recently been reported. Srinivasan and Thirumaran have investigated the influence of pyridine as a ligand in the precursor for the synthesis of CdS nanoparticles. ${ }^{19}$ Onwudiwe et al. synthesized CdS nanoparticles by thermolysis of the 2,2'-bipyridine and 1,10-phenanthroline adduct of cadmium ethyl phenyl dithiocarbamate complexes in hexadecylamine (HDA). ${ }^{20}$ In both studies, the incorporation of nitrogen-donor ligands in the precursor enhances the axial growth direction of CdS nanoparticles. ${ }^{21}$

Various single-source precursors have been used for the preparation of CdS thin films deposition by a number of chemical vapour deposition (CVD) methods. ${ }^{22-25}$ O'Brien and co-workers have reported a number of dithiocarbamatocadmium(II) complexes as single source precursors for CdS thin films using low pressure metal-organic chemical vapour deposition (LP-MOCVD). ${ }^{18,26}$ Aerosol-assisted chemical vapour deposition (AACVD) has been used to deposit a wide range of metal chalcogenide thin films. ${ }^{27-29}$ Several adducts of cadmium dithiocarbamate complexes have recently been reported but without exploring their capabilities as precursors for AACVD. ${ }^{15-17}$ Ehsan et al. used bis( $N, N$-dicyclohexyldithiocarbamato)pyridinecadmium(II) to deposit greenockite CdS thin films which proved to be suitable for application in 
photoelectrochemical (PEC) cells. ${ }^{30} \mathrm{CdS}$ thin films possess good electrical and optical properties, including wide band gaps (ca. $2.4 \mathrm{eV}$ ) making it an ideal material for solar cell device fabrication. $^{31}$

Herein, we report the synthesis and single crystal X-ray structure of the pyridine adduct of bis(piperidinedithiocarbamato)cadmium(II) and we evaluate its potential as a single-source precursor for the deposition of hexagonal CdS thin films and nanoparticles.

\section{Experimental details}

\section{Materials}

Hexadecylamine (HDA) 98\%, tri- $n$-octylphosphine (TOP) 90\%, piperidine $99 \%$ were purchased from Sigma-Aldrich. Petroleum ether, methanol $99.5 \%$, carbon disulfide $99.5 \%$, sodium hydroxide $98 \%$, cadmium chloride $99 \%$, pyridine and acetone were purchased from Saarchem, UnivAR and Merck chemicals. Chemicals were used without further purification.

\section{Characterization of the precursors}

Microanalysis was performed on a Perkin-Elmer automated model 2400 series II CHNS/O analyzer. Infrared spectra were recorded in the range $200-4000 \mathrm{~cm}^{-1}$ using a Bruker FT-IR tensor 27 spectrophotometer. Thermogravimetric analysis was carried out at a $10{ }^{\circ} \mathrm{C} \mathrm{min}{ }^{-1}$ heating rate using a Perkin-Elmer Pyris 6 TGA up to $600{ }^{\circ} \mathrm{C}$ in a closed perforated aluminium pan under $\mathrm{N}_{2}$ gas.

\section{Characterisation of CdS nanoparticles}

Optical absorption measurements were carried out using a Varian Cary 50 UV-visible spectrophotometer. Quartz cuvettes (1 cm path length) were used using toluene as a reference solvent. A Perkin-Elmer LS 55 spectrofluorimeter was used to measure the photoluminescence of the CdS nanoparticles. Transmission electron microscopy (TEM) was performed using a JEOL 1010 TEM, with accelerating voltage of $100 \mathrm{kV}$, Megaview III camera, and Soft Imaging Systems iTEM software. High-resolution transmission electron microscopy (HRTEM) analyses were performed using a JEOL 2010 HRTEM with an accelerating voltage of $200 \mathrm{kV}$. Powder diffraction patterns were recorded in the high angle $2 \theta$ range $\left(20-80^{\circ}\right)$ using a Bruker AXS D8 diffractometer equipped with nickel filtered $\mathrm{Cu}-\mathrm{K}_{\alpha}$ radiation $(\lambda=1.5418 \AA)$ at $40 \mathrm{kV}, 40 \mathrm{~mA}$, room temperature. The scan speed and step sizes were $0.05^{\circ} \mathrm{min}^{-1}$ and $0.00657^{\circ}$ respectively.

\section{Characterisation of CdS thin films}

A Perkin-Elmer Lambda 1050 UV/vis/NIR spectrometer was used to carry out UV-vis absorption measurements of the CdS thin films while photoluminescence properties were measured using an Edinburgh Instruments FLS920 spectrofluorimeter. Films were carbon coated using Edwards E306A coating system prior to scanning electron microscopy (SEM) and energy dispersive X-ray spectroscopy (EDXS) analyses. SEM analysis was performed using a Philips XL-30 FEG scanning electron microscope, and EDXS was carried out using a DX4 detector. Atomic force microscopy (AFM) of CdS thin films was carried out using a Bruker
Multimode 8 instrument. X-ray diffraction studies were performed on a Bruker AXS D8 diffractometer using $\mathrm{Cu}-\mathrm{K}_{\alpha}$ radiation. The samples were mounted flat and scanned between $2 \theta=20-80^{\circ}$.

Single crystal X-ray diffraction data for the compounds were collected using graphite monochromated $\mathrm{Cu}-\mathrm{K}_{\alpha}$ radiation $(\lambda=1.54178 \AA)$ on a Bruker APEX diffractometer. The structure was solved by direct methods and refined by full-matrix least squares on $F^{2}$. All non-H-atoms were refined anisotropically. Hydrogen atoms were included in calculated positions, assigned isotropic thermal parameters and allowed to ride on their parent carbon atoms. All calculations were carried out using the SHELXTL package. The crystallographic refinement parameters are detailed in the next paragraph.

$\mathrm{X}$-ray experimental and structural refinement data for $\left[\mathrm{Cd}\left(\mathrm{S}_{2} \mathrm{C}\left(\mathrm{NC}_{5} \mathrm{H}_{10}\right)\right)_{2}\left(\mathrm{NC}_{5} \mathrm{H}_{5}\right)\right]$ (Fig. 1): $\mathrm{C}_{17} \mathrm{H}_{25} \mathrm{CdN}_{3} \mathrm{~S}_{4}, M=512.04$, monoclinic, space group $P 2(1) / c, a=8.8114(4), b=9.8021(5), c=$ 24.4201(11) $\AA, \alpha\left(^{\circ}\right)=90, \beta\left(^{\circ}\right)=95.928(2), \gamma\left({ }^{\circ}\right)=90$, volume $=$ 2097.89(17) $\AA^{3}, Z=4, D=1.621 \mathrm{mg} \mathrm{m}^{-3}, T=180(2) \mathrm{K}$, reflections collected $=10171 / 3882$, unique reflections $=[R(\mathrm{int})=0.0534]$, final $R$ indices $[I>2 \sigma(I)] R_{1}=0.0349, \mathrm{w} R_{2}=0.0870, R$ indices (all data) $=R_{1}=0.0365, \mathrm{w} R_{2}=0.0882$, largest diff. peak and hole $=$ 0.830 and -0.571 e $\AA^{3}$, GOF $=1.048$. CCDC 984434 .

\section{Synthesis of the precursors}

Organic salts of sodium piperidinedithiocarbamato (ligand), bis(piperidinedithiocarbamato)cadmium(II) and its adduct, bis(piperidinedithiocarbamato)pyridinecadmium(II) were prepared by methods reported previously. ${ }^{9-11,19}$ A brief description of each synthesis is given below.

\section{Preparation of ligands}

Carbon disulfide $(6.0 \mathrm{~mL}, 0.1 \mathrm{~mol})$ was added in small portions to an equimolar solution of sodium hydroxide $(4.0 \mathrm{~g}, 0.1 \mathrm{~mol}$, in

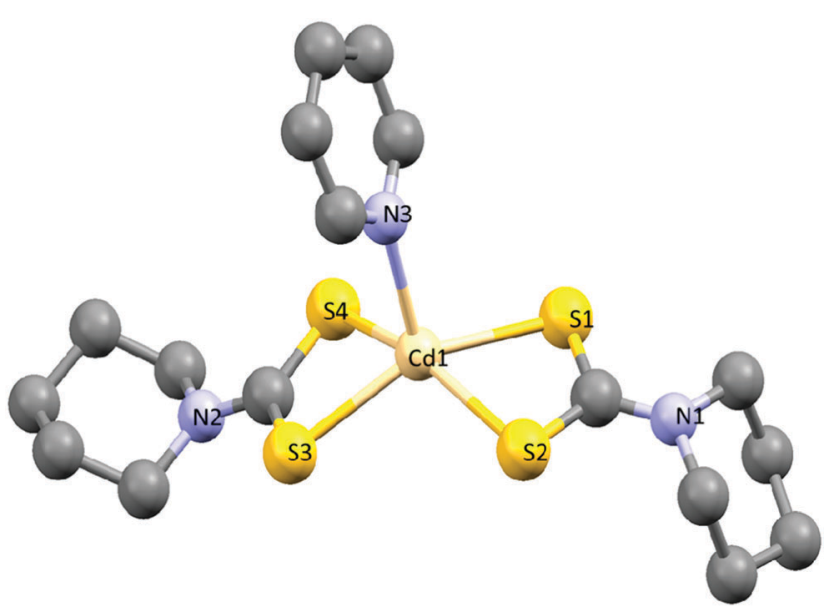

Fig. 1 The X-ray single crystal structure of $\left[\mathrm{Cd}\left(\mathrm{S}_{2} \mathrm{C}\left(\mathrm{NC}_{5} \mathrm{H}_{10}\right)\right)_{2}\left(\mathrm{NC}_{5} \mathrm{H}_{5}\right)\right]$. Selected bond lengths $(\AA \AA)$ and bond angles ( $\left.{ }^{\circ}\right)$; $\mathrm{Cd}(1)-\mathrm{N}(3) 2.320(2), \mathrm{Cd}(1)-$ $\mathrm{S}(3)$ 2.5648(7), $\mathrm{Cd}(1)-\mathrm{S}(2)$ 2.5758(7), $\mathrm{Cd}(1)-\mathrm{S}(1)$ 2.6322(7), $\mathrm{Cd}(1)-\mathrm{S}(4) 2.6684(7)$, $\mathrm{N}(3)-\mathrm{Cd}(1)-\mathrm{S}(3)$ 107.57(6), N(3)-Cd(1)-S(2) 111.32(6), S(3)-Cd(1)-S(2) 106.77(2), $\mathrm{N}(3)-\mathrm{Cd}(1)-\mathrm{S}(1)$ 102.46(6), S(3)-Cd(1)-S(1) 148.57(2), S(2)-Cd(1)-S(1) 69.65(2), $\mathrm{N}(3)-\mathrm{Cd}(1)-\mathrm{S}(4)$ 94.03(6), S(3)-Cd(1)-S(4) 69.25(2), S(2)-Cd(1)-S(4) 153.95(2), $S(1)-C d(1)-S(4) 99.90(2)$. 
$25 \mathrm{~mL}$ of distilled water) and piperidine $(9.8 \mathrm{~mL}, 0.1 \mathrm{~mol})$ cooled in an ice bath at $0{ }^{\circ} \mathrm{C}$. After $15 \mathrm{~min}$, a precipitate formed which was then air dried and recrystallized in a mixture of acetone-petroleum ether. The final product was collected, washed with chloroform and suction dried.

$\mathrm{NaS}_{2} \mathrm{C}\left(\mathrm{NC}_{5} \mathrm{H}_{10}\right)$, yield: $16.4 \mathrm{~g}(90 \%) .{ }^{1} \mathrm{H}$ NMR $(400 \mathrm{MHz}$, $\left.\mathrm{D}_{2} \mathrm{O}\right): \sigma 1.41\left(\mathrm{~m}, 2 \mathrm{H}, 3-\mathrm{CH}_{2}\right), 1.53\left(\mathrm{t}, 2 \mathrm{H}, 4-\mathrm{CH}_{2}\right), 4.28(\mathrm{t}, 2 \mathrm{H}$, 2- $\left.\mathrm{CH}_{2}\right)$. IR ( $\nu_{\max }$ in $\left.\mathrm{cm}^{-1}, \mathrm{ATR}\right): 967, \nu(\mathrm{C}=\mathrm{S}) ; 1468, \nu(\mathrm{C}=\mathrm{N})$. Anal. calc. for $\mathrm{C}_{6} \mathrm{H}_{12} \mathrm{NS}_{2} \mathrm{ONa}(\%)$ : C, 35.8; H, 6.01; N, 6.96. Found (\%): C, 35.9; H, 6.13; N, 6.98.

\section{Preparation of $\left[\mathrm{Cd}\left(\mathrm{S}_{2} \mathrm{C}\left(\mathrm{NC}_{5} \mathrm{H}_{10}\right)\right)_{2}\right]$ complex and its adduct $\left[\mathrm{Cd}\left(\mathrm{S}_{2} \mathrm{C}\left(\mathrm{NC}_{5} \mathrm{H}_{10}\right)\right)_{2}\left(\mathrm{NC}_{5} \mathrm{H}_{5}\right)\right]$}

Cadmium chloride ( $0.92 \mathrm{~g}, 5.0 \mathrm{mmol}$ ) was dissolved in distilled water $(25.0 \mathrm{~mL})$ and added drop-wise to the corresponding solution of the piperidinedithiocarbamato ligand $(10.0 \mathrm{mmol}$, $1.832 \mathrm{~g})$. The reaction mixture was stirred for $1 \mathrm{~h}$, and the precipitate formed was filtered, washed with excess distilled water and dried under vacuum at $70{ }^{\circ} \mathrm{C} .0 .53 \mathrm{~g}(1.0 \mathrm{mmol})$ of the product was dissolved in pyridine (py, $25 \mathrm{~mL}$ ). The light yellow solution obtained was filtered into a beaker and allowed to crystallize at room temperature. After 2 days, the colourless crystals which had formed were isolated by filtration, washed with hexane and dried.

$\left[\mathrm{Cd}\left(\mathrm{S}_{2} \mathrm{C}\left(\mathrm{NC}_{5} \mathrm{H}_{10}\right)\right)_{2}\right]$, yield: $1.71 \mathrm{~g}(79 \%) .{ }^{1} \mathrm{H}$ NMR $\delta \mathrm{ppm}$ (400 MHz, DMSO): $4.13\left(\mathrm{t}, 8 \mathrm{H}, 2-\mathrm{CH}_{2}\right), 1.73\left(\mathrm{t}, 4 \mathrm{H}, 3-\mathrm{CH}_{2}\right), 1.63$ $\left(\mathrm{m}, 8 \mathrm{H}, 3-\mathrm{CH}_{2}\right)$, IR $\left(\nu_{\max }\right.$ in $\left.\mathrm{cm}^{-1}, \mathrm{ATR}\right): 967, \nu(\mathrm{C}=\mathrm{S}) ; 1485$, $\nu(\mathrm{C}=\mathrm{N})$; 388, $\nu(\mathrm{Cd}-\mathrm{S})$. Anal. calc. for $\mathrm{C}_{12} \mathrm{H}_{20} \mathrm{~N}_{2} \mathrm{~S}_{4} \mathrm{Cd}(\%)$ : , 33.29; H, 4.66; N, 6.47. Found (\%): C, 33.47; H, 4.55; N, 6.43.

$\left[\mathrm{Cd}\left(\mathrm{S}_{2} \mathrm{C}\left(\mathrm{NC}_{5} \mathrm{H}_{10}\right)\right)_{2}\left(\mathrm{NC}_{5} \mathrm{H}_{5}\right)\right]$, yield: $0.61 \mathrm{~g}$ (97\%). IR $\left(\nu_{\max }\right.$ in $\mathrm{cm}^{-1}$, ATR): 989, $\nu(\mathrm{C}=\mathrm{S}) ; 1544, \nu(\mathrm{C}=\mathrm{N}) ; 402, \nu(\mathrm{Cd}-\mathrm{S})$. Anal. calc. for $\mathrm{C}_{17} \mathrm{H}_{25} \mathrm{~N}_{3} \mathrm{~S}_{4} \mathrm{Cd}$ (\%): C, 39.87; H, 4.92; N, 8.21. Found (\%): C, 39.08; H, 4.32; N, 7.69.

\section{Preparation of cadmium sulfide (CdS) nanoparticles}

Cadmium sulfide nanocrystals were prepared by decomposition of $\left[\mathrm{Cd}\left(\mathrm{S}_{2} \mathrm{C}\left(\mathrm{NC}_{5} \mathrm{H}_{10}\right)\right)_{2}\left(\mathrm{NC}_{5} \mathrm{H}_{5}\right)\right]$ in hexadecylamine (HDA). In a typical reaction, HDA $(6 \mathrm{~mL})$ was heated to $190{ }^{\circ} \mathrm{C}$ in a three necked flask, and then purged with $\mathrm{N}_{2} \cdot 0.5 \mathrm{~g}$ of precursor was dispersed in $6.0 \mathrm{~mL}$ of TOP. The resultant solution was then injected into $6.0 \mathrm{~g}$ of hot HDA in a three necked flask. The temperature was maintained for one hour and the mixture was allowed to cool at room temperature. Addition of methanol $(45 \mathrm{~mL})$ produced a yellow precipitate which was separated by centrifugation. The yellow residue was washed twice with methanol and redispersed in toluene for further characterisation.

\section{Aerosol assisted chemical vapour deposition of CdS thin films}

CdS thin films were grown on glass substrates under an argon flow of $160 \mathrm{~mL} \mathrm{~min}^{-1}$ using chloroform as solvent at deposition temperatures of $350{ }^{\circ} \mathrm{C}, 400{ }^{\circ} \mathrm{C}$ and $450{ }^{\circ} \mathrm{C}$. In a typical deposition, $0.2 \mathrm{~g}(0.4 \mathrm{mmol})$ of the precursor was dissolved in chloroform $(10 \mathrm{~mL})$ in a two-necked $100 \mathrm{~mL}$ round-bottom flask with a gas inlet that allowed the carrier gas (argon) to pass into the solution to aid the transport of the aerosol which had been produced using a commercially available humidifier unit.
This flask was connected to the reactor tube by a piece of reinforced tubing. The argon flow rate was controlled by a Platon flow gauge. Seven glass substrates were placed inside the reactor tube, which is then placed in a Carbolite furnace.

\section{Results and discussion}

The pyridine adduct of cadmium piperidine dithiocarbamate complex was synthesized by the reaction of excess pyridine with parent material complex. The complexes are air and moisture stable. In our previous work we synthesized CdS nanoparticles using the cadmium piperidine dithiocarbamate (DTC) and cadmium tetrahydroisoquinoline dithiocarbamate complexes as single source precursors. ${ }^{9,10}$ In this work we studied the effect of pyridine in the complex, on the shape of CdS nanoparticles at different reaction temperatures. Additionally, AACVD was performed to deposit CdS thin films at different temperatures.

The single crystal X-ray structure of bis(piperidinedithiocarbamato)pyridinecadmium(II) $\left[\mathrm{Cd}\left(\mathrm{S}_{2} \mathrm{C}\left(\mathrm{NC}_{5} \mathrm{H}_{10}\right)\right)\left(\mathrm{NC}_{5} \mathrm{H}_{5}\right)\right]$, is shown in Fig. 1. There are three coordinating ligands of two different molecules in the symmetric unit of the complex. Coordination to the central $\mathrm{Cd}$ (II) metal is characterised by $4 \times \mathrm{S}$ and $1 \times \mathrm{N}$ bonds from two piperidine dithiocarbamate (bidentate) and pyridine ligands, respectively forming a five coordinated complex. The geometry of the complex is a square pyramidal. The bond lengths of $\mathrm{Cd}-\mathrm{S}$ range from 2.5648 to $2.6684 \AA$, which are longer than that of $\mathrm{Cd}-\mathrm{N}(2.320 \AA)$ as expected. Two of the Cd-S bond lengths are relatively longer than the other two in each dithiocarbamato ligand as observed previously. ${ }^{32}$ Structural refinement data are given in the experimental; selected bond angles and lengths are presented in the caption to Fig. 1.

Thermogravimetric analysis (TGA) gives insight into the decomposition of precursors and what products might be expected. TGA of the pyridine adduct of bis(piperidine dithiocarbamato)cadmium(II) complex reveal a two-step decomposition with weight loss between ca. 130 and $320{ }^{\circ} \mathrm{C}$ (Fig. 2). The solid decomposition residue amounts to $31 \%$ for the pyridine adduct which is close to the calculated value of $28 \%$ for CdS for this complex. Previous studies on the cadmium piperidine dithiocarbamate complexes had steep one-step decomposition with a rapid weight loss at $329{ }^{\circ} \mathrm{C}$, mirrored in the second decomposition step of the pyridine adduct. ${ }^{10}$ In the case of the adduct, the first decomposition temperature is due to the loss of the pyridine ligand, confirmed by the percentage loss of $14.1 \%$ from the TGA plot.

CdS nanoparticles were synthesis from the thermolysis of $\left[\mathrm{Cd}\left(\mathrm{S}_{2} \mathrm{C}\left(\mathrm{NC}_{5} \mathrm{H}_{10}\right)\right)_{2}\left(\mathrm{NC}_{5} \mathrm{H}_{5}\right)\right]$ in hexadecylamine at various temperatures, and their optical properties were tested. Usually, two photoluminescence (PL) emission peaks can be observed from semiconductor nanoparticles. The first is excitonic emission which is sharp and located near the absorption edge of the particle and a second deep trap emission which is broad and Stokes shifted compared to the excitonic emission. ${ }^{33,34}$ The UV-vis absorption 


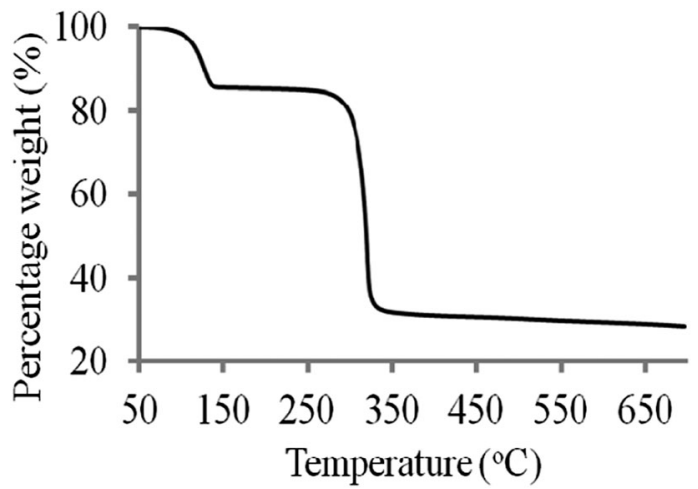

Fig. 2 Thermogravimetric analysis (TGA) plot of the pyridine adduct $\left[\mathrm{Cd}\left(\mathrm{S}_{2} \mathrm{C}\left(\mathrm{NC}_{5} \mathrm{H}_{10}\right)\right)_{2}\left(\mathrm{NC}_{5} \mathrm{H}_{5}\right)\right]$ at a heating rate of $10{ }^{\circ} \mathrm{C} \mathrm{min}^{-1}$ under a nitrogen atmosphere.

spectrum for CdS nanoparticles synthesized at $190{ }^{\circ} \mathrm{C}$ reveal a sharp absorption band edge at $468 \mathrm{~nm}$ (Fig. 3(A)). The corresponding PL spectrum displays a narrow band edge emission, with a maximum at $478 \mathrm{~nm}$ (Fig. 3(A)). The bathochromic shift observed is typical for nanostructured semiconductors. ${ }^{35,36}$ There is also a weaker broad emission observed in the 560-670 nm regions which is most likely due to electron-hole recombination from surface defects. The Stokes shift observed is typical for nanostructured semiconductors. ${ }^{35,36}$

The effect of reaction temperature on the optical absorption of CdS nanoparticles has been investigated. The absorption spectra for CdS nanoparticles synthesized at 190, 230 and $270{ }^{\circ} \mathrm{C}$ are shown in Fig. 3(B). The well-defined absorption band edge at $468 \mathrm{~nm}$ observed for the CdS synthesized at $190{ }^{\circ} \mathrm{C}$ is less prominent for the samples synthesized at 230 and $270{ }^{\circ} \mathrm{C}$. The band edge for CdS nanoparticles synthesised at $230{ }^{\circ} \mathrm{C}$ is observed at $479 \mathrm{~nm}$, while the band edge of CdS nanoparticles synthesised at $270{ }^{\circ} \mathrm{C}$ is further red-shifted to $496 \mathrm{~nm}$. Reaction time produced negligible effects in the optical spectra; samples were collected after 1 and 2 hours with little changes in the absorption and emission spectra. The formation of CdS nanocrystals was also monitored with UV-vis absorption spectroscopy. As nanoparticles grow in size, the bandgap absorption edge is bathochromically shifted. Upon increase of the reaction temperature from $190{ }^{\circ} \mathrm{C}$ to $270{ }^{\circ} \mathrm{C}$, the growth rate of the CdS nanocrystals is increased. A potential reason for this phenomenon could be that higher reaction temperature results in the formation of irregular nanoparticles with reduced crystallinity due to random, faster nucleation and with the rapid growth affecting the ligand configuration at the nanocrystal surface. ${ }^{37}$

TEM and HRTEM images of the CdS nanoparticles synthesised from $\left[\mathrm{Cd}\left(\mathrm{S}_{2} \mathrm{C}\left(\mathrm{NC}_{5} \mathrm{H}_{10}\right)\right)_{2}\left(\mathrm{NC}_{5} \mathrm{H}_{5}\right)\right]$ at 190,230 and $270{ }^{\circ} \mathrm{C}$ are shown in Fig. 4(a)-(f). The CdS nanoparticles obtained at low temperature $\left(190{ }^{\circ} \mathrm{C}\right)$ are rod shaped (Fig. 4(a)) with a length of $64.38 \pm 4.62 \mathrm{~nm}$, a width of $5.20 \pm 0.98 \mathrm{~nm}$ and an aspect ratio of 12.38. Similar morphologies were obtained using $\left[\mathrm{Cd}\left(\mathrm{S}_{2} \mathrm{CNC}_{5} \mathrm{H}_{10}\right)_{2}\right]$ as a precursor whereby multiple-armed rods of CdS were obtained. ${ }^{9-11}$ When the reaction temperature was increased to $230{ }^{\circ} \mathrm{C}$ (Fig. 4(c)), rods with a reduced average
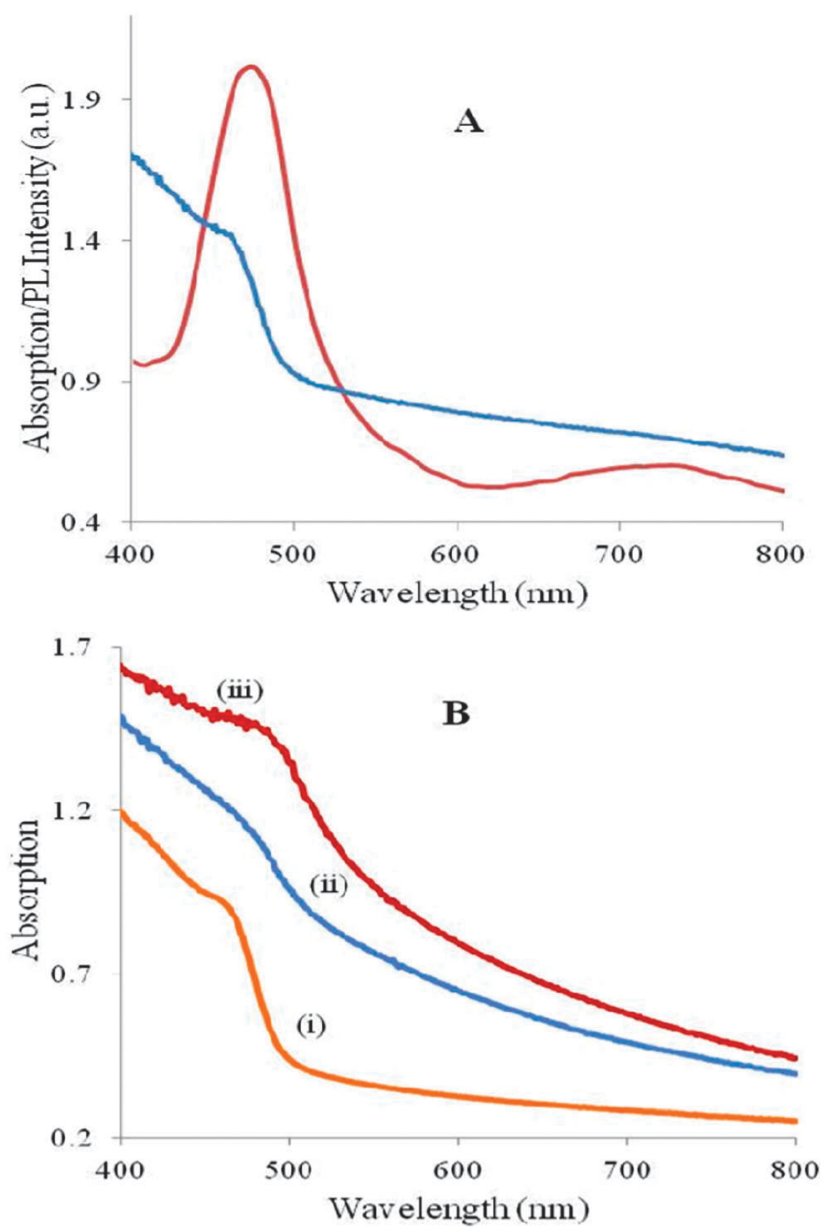

Fig. 3 (A) UV-vis absorption (blue) and PL (red) spectra of HDA capped CdS nanoparticles at $190{ }^{\circ} \mathrm{C}$ and (B) combined UV-vis absorption spectra for CdS nanoparticles synthesized at (i) $190{ }^{\circ} \mathrm{C}$, (ii) $230{ }^{\circ} \mathrm{C}$ and (iii) $270{ }^{\circ} \mathrm{C}$ reaction temperatures. PL spectra are corrected for instrument response.

length of $24.84 \pm 4.42 \mathrm{~nm}$ and breadth of $6.58 \pm 1.02 \mathrm{~nm}$ were obtained. The corresponding HRTEM images (Fig. 4(b) and (d)) show particles with lattice fringes. The particles synthesized at $230{ }^{\circ} \mathrm{C}$ have lattice fringes with a $d$-spacing of $3.15 \AA$ corresponding to the (002) plane of hexagonal CdS. At $270{ }^{\circ} \mathrm{C}$, the shape of the CdS nanoparticles evolved from rod to an oval shaped morphology with diameters ranging from 16.8 to $23.3 \mathrm{~nm}$ (Fig. 4(f)); the aspect ratio of the nanorods decreased with the increase in temperature. ${ }^{37}$ The oval shape of the particles was confirmed by the HRTEM image (Fig. 4(f)). The lattice fringes have a $d$-spacing of $3.13 \AA$ corresponding to the (002) basal plane of hexagonal CdS. In summary, CdS nanoparticles synthesized at higher temperature, favour the thermodynamic growth regime resulting in isotropic particles (spherical and cubes) while CdS nanoparticles synthesised at lower temperatures favour non-equilibrium kinetic growth regime and yields anisotropic particles (rods). ${ }^{38}$

The powder X-ray diffraction (p-XRD) patterns of the CdS nanoparticles grown at various temperatures are shown in Fig. 5 , and could all be indexed to the hexagonal phase of CdS (card number: 03-065-3414). Diffraction peaks at $2 \theta=24.80^{\circ}, 26.32^{\circ}$, 

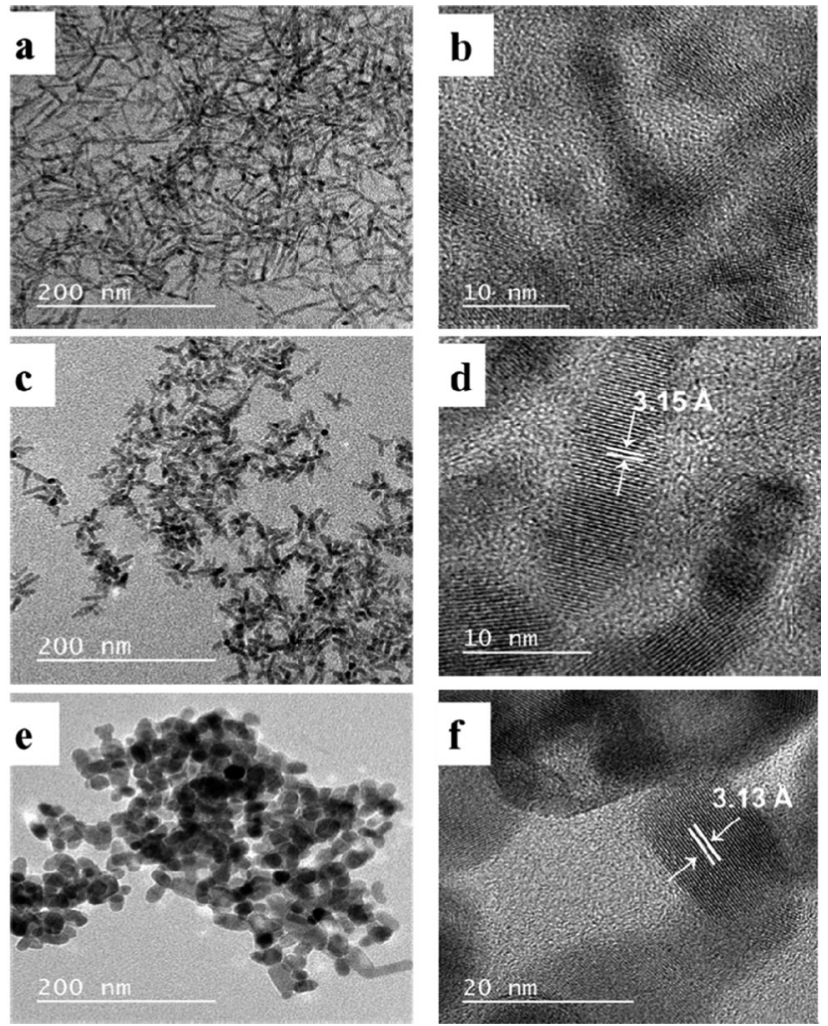

Fig. 4 TEM and HRTEM images of HDA capped CdS nanoparticles synthesized by thermolysis of $\left[\mathrm{Cd}\left(\mathrm{S}_{2} \mathrm{C}\left(\mathrm{NC}_{5} \mathrm{H}_{10}\right)\right)_{2}\left(\mathrm{NC}_{5} \mathrm{H}_{5}\right)\right]$ at temperatures of (a, b) $190{ }^{\circ} \mathrm{C}$, (c, d) $230{ }^{\circ} \mathrm{C}$ and $(e, f) 270{ }^{\circ} \mathrm{C}$.

$28.12^{\circ}, 43.70^{\circ}, 47.82^{\circ}$ and $51.82^{\circ}$ which correspond to the (100), (002), (101), (110), (103) and (112) planes of hexagonal CdS respectively were observed in the diffraction patterns. The high intensity and narrower (002) peak in p-XRD pattern of CdS nanoparticles indicate that the nanoparticles were elongated along the $c$-axis. ${ }^{21}$

CdS thin films were deposited by AACVD on glass substrates using $\left[\mathrm{Cd}\left(\mathrm{S}_{2} \mathrm{C}\left(\mathrm{NC}_{5} \mathrm{H}_{10}\right)\right)_{2}\left(\mathrm{NC}_{5} \mathrm{H}_{5}\right)\right]$ as precursor and deposition

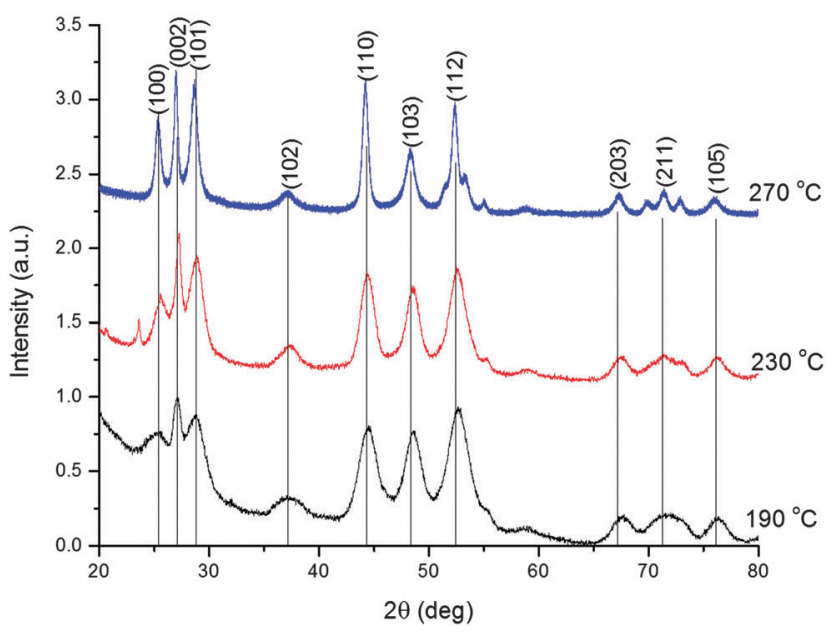

Fig. 5 p-XRD patterns of the hexagonal CdS nanoparticles. Spectra are offset in $y$ for clarity.
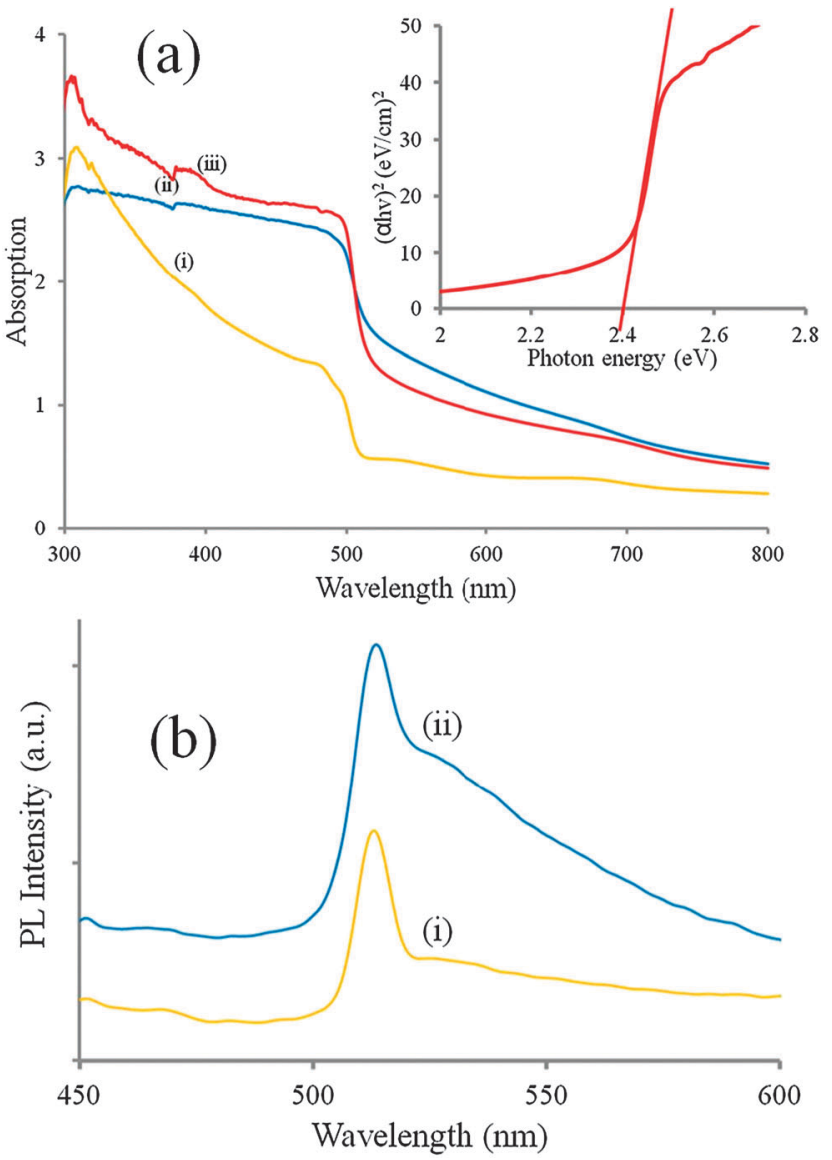

Fig. 6 (a) UV-vis absorption of CdS thin films deposited by AACVD at (i) $350{ }^{\circ} \mathrm{C}$, (ii) $400{ }^{\circ} \mathrm{C}$ and (iii) $450{ }^{\circ} \mathrm{C}$. Inset: Tauc plot showing the estimated optical band gap $(2.4 \pm 0.2 \mathrm{eV})$. (b) Photoluminescence emission spectra of $\mathrm{CdS}$ thin films at (i) $350{ }^{\circ} \mathrm{C}$ and (ii) $400{ }^{\circ} \mathrm{C}\left(\lambda_{\text {exc }}=350 \mathrm{~nm}\right)$. PL spectra are corrected for instrument response.

temperatures of $350{ }^{\circ} \mathrm{C}, 400{ }^{\circ} \mathrm{C}$ and $450{ }^{\circ} \mathrm{C}$. The UV-vis absorption spectra of the CdS thin films are shown in Fig. 6(a). The sharp absorption edges of the samples at $c a .516 \mathrm{~nm}$ confirm the energy of the optical band gap. The optical features of the CdS films were not significantly affected by deposition temperature, with an excitonic peak around $496 \mathrm{~nm}(2.5 \mathrm{eV})$; the band gaps estimated are commensurate with those previously reported for CdS thin films. ${ }^{39,40}$ The variation of the fluorescence spectrum of the CdS thin films with reaction temperature is shown in Fig. 6(b). There is one narrow and sharp emission peak in the photoluminescence (PL) spectrum due to excitonic emission for the CdS films deposited at $350{ }^{\circ} \mathrm{C}$ and $400{ }^{\circ} \mathrm{C}$ located at around $510 \mathrm{~nm}$. The sharp excitonic emission peaks located near the absorption edge of the films are due to fewer surface trap states. ${ }^{41} \mathrm{CdS}$ thin films deposited at $450{ }^{\circ} \mathrm{C}$ display a much more undefined and broader emission profile (Fig. S1, ESI $\dagger$ ).

SEM studies show that the morphology of the CdS films change with deposition temperature. CdS films synthesized at $350{ }^{\circ} \mathrm{C}$ have regular hexagonal-like domains (Fig. 7). These structures are approximately $310 \mathrm{~nm}$ in size with uniform coverage on the substrate $\mathrm{CdS}$ films synthesized at $400{ }^{\circ} \mathrm{C}$ have a surface showing various morphological features with sizes 

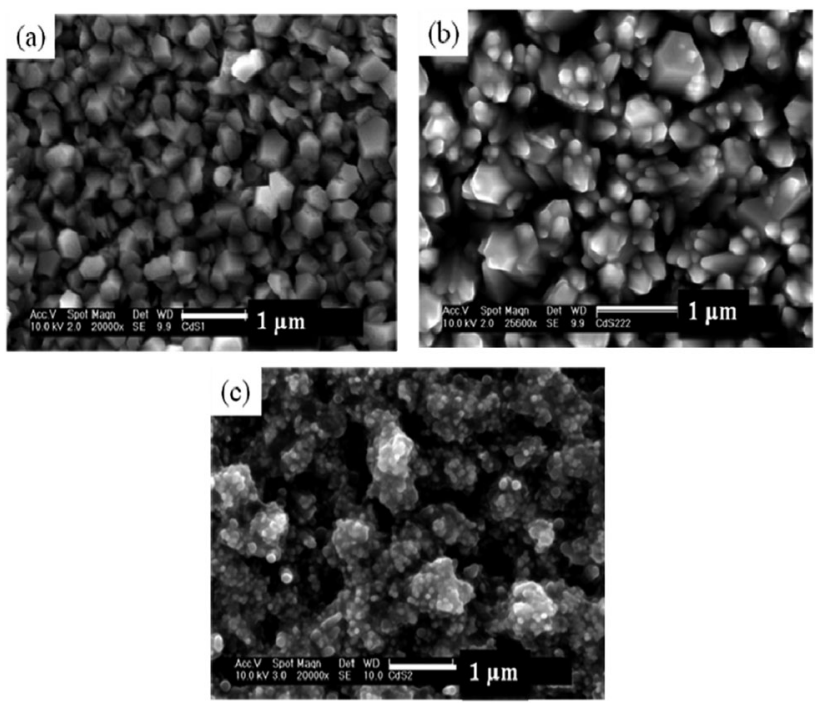

Fig. 7 SEM images of $\mathrm{CdS}$ thin films deposited at (a) $350{ }^{\circ} \mathrm{C}$, magn $20000 \times$; (b) $400{ }^{\circ} \mathrm{C}$, magn. $2560 \times$ and (c) $450{ }^{\circ} \mathrm{C}$, magn. $20000 \times$.

ranging from $200 \mathrm{~nm}$ to $500 \mathrm{~nm}$. There is a further change of morphology for films deposited at $450{ }^{\circ} \mathrm{C}$, where close to spherical granules are observed. The coverage is non-uniform with clustered growth predominant on the substrate. Films deposited using the parent piperidine dithiocarbamate complex at similar deposition temperatures show faceted morphology with uniform film coverage (Fig. S2, ESI $\dagger$ ). The films obtained at $400{ }^{\circ} \mathrm{C}$ show the presence of some rod-like structures. Energy dispersive X-ray spectroscopy (EDXS) at 20 $\mathrm{kV}$ confirmed the stoichiometry of CdS thin films deposited at $350{ }^{\circ} \mathrm{C}, 400{ }^{\circ} \mathrm{C}$ and $450{ }^{\circ} \mathrm{C}$ (Table 1 ).

The surface topography of the as-deposited CdS films was investigated by scanning probe atomic force microscopy (AFM). Fig. 8 shows height profiles of CdS films deposited at various temperatures on glass substrates. AFM of the CdS films deposited show the presence of uniform and crack-free surface morphologies characterized by well-interconnected spherical crystallites. The typical root-mean square roughness ( $\mathrm{Rq}$ ) was $16.9 \mathrm{~nm}, 17.8 \mathrm{~nm}$ and $22.7 \mathrm{~nm}$ at deposition temperatures of (a) $350{ }^{\circ} \mathrm{C}$, (b) $400{ }^{\circ} \mathrm{C}$ and (c) $450{ }^{\circ} \mathrm{C}$ respectively. The increase in surface roughness with increasing deposition temperature is associated with an increase in grain size. It is evident that the deposition temperature of the thin film modifies the grain sizes as well as the surface roughness. An even and regular morphology is required for respectable performance in photovoltaic devices. $^{42}$

The crystalline structure of the as-grown CdS thin films deposited onto glass substrates were confirmed by p-XRD using

Table 1 Elemental analysis by EDXS (atomic \%) of CdS thin films at three different deposition temperatures

\begin{tabular}{llll}
\hline Temperature $\left({ }^{\circ} \mathrm{C}\right)$ & Cd at\% & S at\% & Cd/S ratio \\
\hline 350 & 50.4 & 49.6 & 1.02 \\
400 & 51.5 & 48.5 & 1.06 \\
450 & 53.0 & 47.0 & 1.13
\end{tabular}
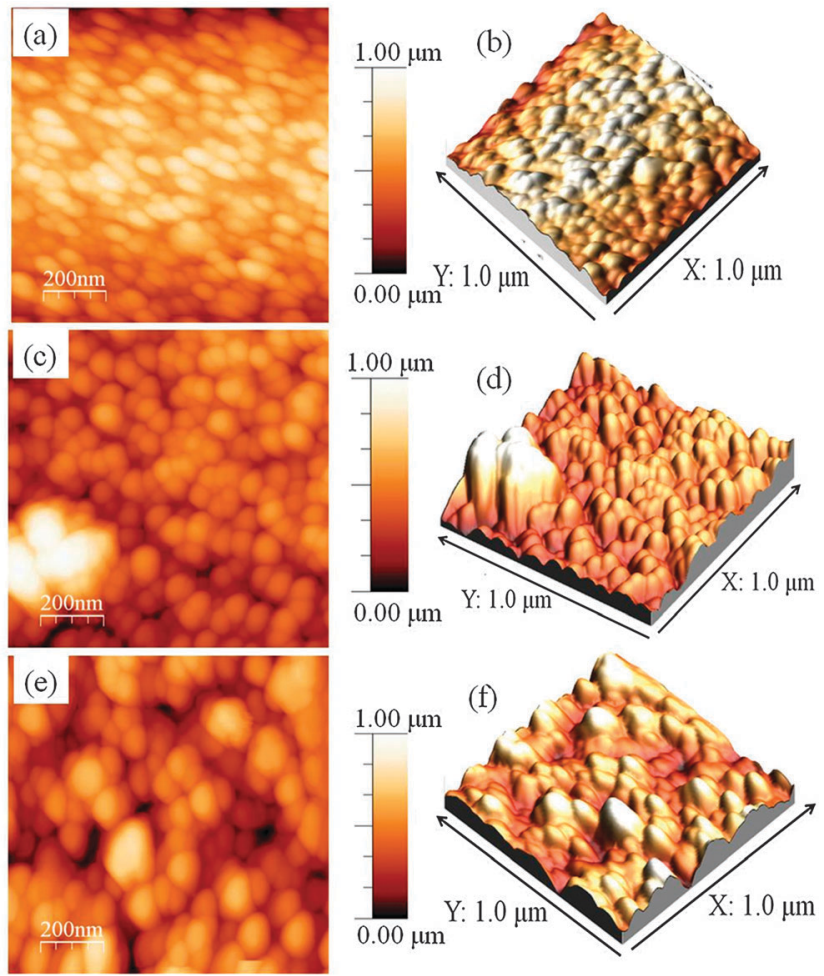

Fig. 8 2-D and 3-D AFM height profiles of CdS thin films deposited by AACVD at (a and b) $350{ }^{\circ} \mathrm{C}$, (c and d) $400{ }^{\circ} \mathrm{C}$ and (e and f) $450{ }^{\circ} \mathrm{C}$.

Cu $\mathrm{K}_{\alpha}(\lambda=1.5406 \AA)$ radiation, with measurements in the $2 \theta$ range of 20 to $80^{\circ}$. The diffraction patterns of CdS thin films (Fig. 9) indicate the crystalline nature of films with the greenockite (hexagonal) structure (JCPDS card no 04-002-3090). The seven reflections at $2 \theta$ correspond to the $(h k l)$ planes $(100)$, (002), (101), (102), (110), (103) and (112) respectively; confirming that the product formed is pure crystalline CdS. There are no signs of any crystalline impurities such as elemental cadmium, sulfur and CdO.

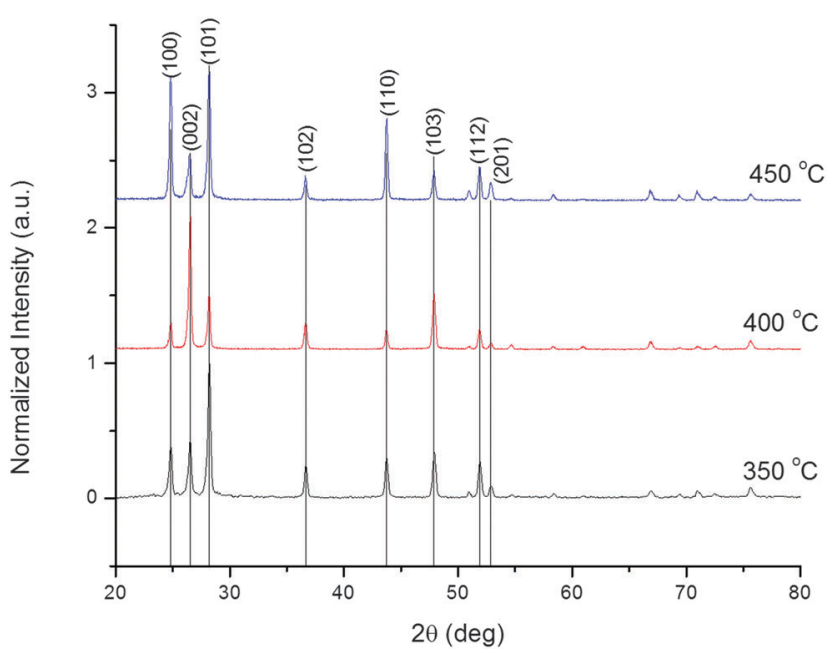

Fig. 9 p-XRD pattern of greenockite CdS thin films deposited by AACVD. 


\section{Conclusions}

The structure of the pyridine adduct of bis(piperidine dithiocarbamato)cadmium(II) has been elucidated and its use as a precursor for CdS nanoparticles and thin films have been established. The HDA-capped CdS nanoparticles synthesized at $190{ }^{\circ} \mathrm{C}$ shows a sharp absorption band edge, with corresponding narrow Stokes shifted photoluminescence emission. Predominantly rod-shaped morphology was observed for particles synthesized at lower reaction temperatures, whereas oval shaped particles were observed at higher reaction temperatures. CdS thin films deposited by AACVD on glass substrates at a range of temperatures consisted of faceted hexagonal-like particles at lower reaction temperatures, with clustered growth observed at higher temperatures. Both SEM and AFM confirmed the uniform surface coverage of the films. The hexagonal phase was dominant for both the nanoparticles and thin films, as evidenced by $\mathrm{p}$-XRD measurements.

\section{Acknowledgements}

The authors are grateful to the National Research Foundation (NRF), Department of Science and Technology (DST) South Africa, India-Brazil-South Africa Project (IBSA) and Royal Society Leverhulme Africa Award for financial support. The authors also thank the Centre for Electron Microscopy, University of Kwa-Zulu Natal for transmission electron microscopy measurements. This work was also funded by the U.K. Engineering and Physical Sciences Research Council (Core Capability in Chemistry, EPSRC grant number EP/K039547/1). We thank Dr Louise Natrajan (University of Manchester) for access to the EI spectrofluorimeter and Dr Chris Muryn (University of Manchester) for maintaining the AFM instrument used in these studies.

\section{Notes and references}

1 G. Hogarth, Mini-Rev. Med. Chem., 2007, 12(12), 1202.

2 T. Trindade and P. O'Brien, J. Mater. Chem., 1996, 6, 343.

3 M. Lazell and P. O’Brien, Chem. Commun., 1999, 2041.

4 M. A. Malik, N. Revaprasadu and P. O'Brien, Chem. Mater., 2001, 13, 913.

5 P. S. Nair, T. Radhakrishnan, N. Revaprasadu, G. A. Kolawole and P. O'Brien, Chem. Commun., 2002, 564.

6 P. S. Nair, T. Radhakrishnan, N. Revaprasadu and P. O’Brien, Mater. Sci. Technol., 2005, 21, 237.

7 A. A. Memon, M. Afzaal, M. A. Malik, C. Q. Nguyen, P. O'Brien and J. Raftery, Dalton Trans., 2006, 4499.

8 A. L. Abdelhady, M. Afzaal, M. A. Malik and P. O'Brien, J. Mater. Chem., 2011, 21, 18768.

9 T. P. Mthethwa, V. S. R. Rajasekhar Pullabhotla, P. S. Mdluli, J. WesleySmith and N. Revaprasadu, Polyhedron, 2009, 28, 2977.

10 L. D. Nyamen, V. S. R. Rajasekhar Pullabhotla, A. A. Nejo, P. Ndifon and N. Revaprasadu, New J. Chem., 2011, 35, 1133.
11 L. D. Nyamen, N. Revaprasadu, V. S. R. Rajasekhar Pullabhotla, A. A. Nejo, P. T. Ndifon, M. A. Malik and P. O'Brien, Polyhedron, 2013, 56, 62.

12 G. Hogarth, Prog. Inorg. Chem., 2005, 53, 71.

13 E. R. T. Tiekink and I. Haiduc, Prog. Inorg. Chem., 2005, 54, 127.

14 P. Popluakhin and E. R. T. Tiekink, Acta Crystallogr., Sect. E: Struct. Rep. Online, 2008, E64, m1176.

15 P. A. Ajibade and D. C. Onwudiwe, J. Mol. Struct., 2013, 1034, 249.

16 N. Srinivasan, P. J. Rani and S. Thirumaran, J. Coord. Chem., 2009, 62, 1271.

17 P. V. Subha, P. Valarmathi, N. Srinivasan, S. Thirumaran and K. Saminathan, Polyhedron, 2010, 29, 1078.

18 M. Chunggaze, M. A. Malik and P. O'Brien, Adv. Mater. Opt. Electron., 1997, 7, 311.

19 N. Srinivasan and S. Thirumaran, Superlattices Microstruct., 2012, 51, 912.

20 C. D. Onwudiwe, C. A. Strydom and O. S. Oluwafemi, New J. Chem., 2013, 37, 834.

21 P. Yan, Y. Xie, Y. Qian and X. Liu, Chem. Commun., 1999, 1293.

22 D. Barreca, A. Gasparotto, C. Maragno, R. Seraglia, E. Tondello, A. Venzo, V. Krishnan and H. Bertagnolli, Appl. Organomet. Chem., 2005, 19, 59.

23 K. S. Youn, K. H. Yu, J. S. Song and I. H. Choi, J. Korean Phys. Soc., 2005, 47(1), 89.

24 S. H. Yoon, S. S. Lee, K. W. Seo and I.-W. Shim, Bull. Korean Chem. Soc., 2006, 27, 2071.

25 A. S. R. Chesman, N. W. Duffy, A. Martucci, L. De Oliveira Tozi, Th. Birendra Singha and J. J. Jasieniak, J. Mater. Chem. C, 2014, 2, 3247.

26 D. M. Frigo, O. F. Z. Khan and P. O'Brien, J. Cryst. Growth, 1989, 96, 989.

27 K. Ramasamy, M. A. Malik, M. Helliwell, J. Raftery and P. O’Brien, Chem. Mater., 2011, 23, 1471.

28 D. Oyetunde, M. Afzaal, M. A. Vincent, I. H. Hillier and P. O’Brien, Inorg. Chem., 2011, 50, 2052.

29 I. D. Rojas-Montoya, A. Santana-Silva, V. García-Montalvo, M.-Á. Muñoz-Hernández and M. Rivera, New J. Chem., 2014, 38, 4702.

30 M. A. Ehsan, H. N. Ming, M. Misran, Z. Arifin, E. R. T. Tiekink, A. P. Safwan, M. Ebadi, W. J. Basirun and M. Mazhar, Chem. Vap. Deposition, 2012, 18, 191.

31 A. Bayer, D. S. Boyle, M. R. Heinrich, P. O’Brien, D. J. Otway and O. Robbe, Green Chem., 2000, 79.

32 S. Thirumaran, K. Ramalingam, G. Bocelli and L. Righi, Polyhedron, 2009, 28, 263.

33 M. Nell, J. Marohn and G. Mclendon, J. Phys. Chem. B, 1990, 94, 4359.

34 L. Spanhel, M. Haase, H. Weller and A. Henglein, J. Am. Chem. Soc., 1987, 109, 5649.

35 M. A. Malik, P. O’Brien and N. Revaprasadu, S. Afr. J. Sci., 2000, 96, 55.

36 M. Green and P. O'Brien, Chem. Commun., 1999, 2235.

37 M. Nell, J. Marohn and G. Mclendon, J. Phys. Chem. B, 1990, 94, 4359. 
38 L. Spanhel, M. Haase, H. Weller and A. Henglein, J. Am. Chem. Soc., 1987, 109, 5649.

39 Y. Li, X. Li, C. Yang and Y. Li, J. Mater. Chem., 2003, 13, 2641.

40 K.-T. Yong, Y. Sahoo, M. T. Swihart and P. N. Prasad, J. Phys. Chem. C, 2007, 111, 2447.
41 S. A. Vanalakar, S. S. Mali, R. C. Pawar, N. L. Tarwal, A. V. Moholkar, J. A. Kim, Y. Kwon, J. H. Kim and P. S. Patil, Electrochim. Acta, 2011, 56, 2762.

42 M. Tsuji, T. Aramoto, H. Ohyama, T. Hibino and K. Omura, Jpn. J. Appl. Phys., Part 1, 2000, 39, 3902. 